\title{
Serum Fibrinogen Is An Independent Prognostic Factor In Operable Esophageal Squamous Carcinoma: A Real-World Study
}

This article was published in the following Dove Press journal: Cancer Management and Research

\author{
Yan Zheng (iD ${ }^{1, *}$ \\ Yin $\mathrm{Li}^{1,2, *}$ \\ Wenqun Xing $^{1, *}$ \\ Jianjun Qin ${ }^{1,2}$ \\ Xianben Liu' \\ Ruixiang Zhang' \\ Haibo Sun' \\ Xiankai Chen ${ }^{1,2}$ \\ 'Department of Thoracic Surgery, The \\ Affiliated Cancer Hospital of Zhengzhou \\ University, Henan Cancer Hospital, \\ Zhengzhou, Henan 450008, People's \\ Republic of China; ${ }^{2}$ Department of \\ Thoracic Surgery, National Cancer \\ Center/National Clinical Research \\ Center for Cancer/Cancer Hospital, \\ Chinese Academy of Medical Sciences \\ and Peking Union Medical College, Beijing \\ I0002I, People's Republic of China
}

*These authors contributed equally to this work
Correspondence: $Y$ in $\mathrm{Li}$

The Affiliated Cancer Hospital of Zhengzhou University/Henan Cancer Hospital, 127\# Dongming Road, Zhengzhou 450000, People's Republic of China

Tel +86 37I 65587226

Email liyin0825@hotmail.com
Purpose: To fully elucidate the relationship of serum fibrinogen and the prognosis of esophageal squamous cell carcinoma.

Methods: The concentrations of serum fibrinogen were measured by the Clauss method in a total of 1331 operable esophageal squamous cell carcinoma (ESCC) patients from the past 3 years. The correlation of serum fibrinogen concentration and patient outcome and clinical pathological factors was tested.

Results: Hyperfibrinogenemia was significantly correlated with advanced pathological $\mathrm{T}$ stage and TNM stage. Serum fibrinogen was determined as a worse independent survival predictor in ESCC by survival analysis. The hazard ratio was 1.672 ( $95 \%$ confidence interval [CI] 1.043-2.681). A subgroup analysis further elucidated a significant correlation between hyperfibrinogenemia and younger age $(\mathrm{P}=0.011)$, being female $(\mathrm{P}=0.002)$, not having a history of smoking $(\mathrm{p}<0.001)$ or alcohol consumption $(\mathrm{p}<0.001)$, pathological N0 stage $(\mathrm{P}=0.002)$, and early pathological TNM stage (I-II) $(\mathrm{P}=0.004)$.

Conclusion: This research showed that preoperative serum fibrinogen is an independent prognostic factor for survival in ESCC, especially for the early pathological TNM stage (I-II) and N0 patients.

Keywords: esophageal cancer, serum fibrinogen, prognostic factor, retrospective study, real world study

\section{Introduction}

Oesophageal cancer is one of the most common cancers worldwide, with over 400,000 deaths annually. ${ }^{1}$ It ranked as the fourth leading cause of cancer-related death in China. ${ }^{2}$ Approximately 53\% of ESCC cases occur in China, whereas the predominant subtype in Western countries is AC. ${ }^{3}$ Although improvements have been made in early diagnosis, better surgical techniques and multimodal treatment (chemotherapy, radiotherapy and surgery), recurrence cannot be easily avoided in most patients and the prognosis of ESCC still remains unsatisfactory. ${ }^{4}$ Clinically, many patients with similar pathological TNM stages and histologic classification have remarkably different survival outcomes. Some of the patients still experience recurrence within a short time, even with early TNM stages. The progression of ESCC is considered a multistep process that involves oncogenes and related proteins. ${ }^{5}$ Protein expression profiles may reflect the prognosis of the ESCC. ${ }^{6}$ Many researchers have attempted to find biomarkers to predict the overall survival of ESCC. ${ }^{6}$ Although numerous biomarkers have been suggested as potential prognosis factors of ESCC, there are still none that could be used for daily clinical work. 
Fibrinogen plays an important role in regulating blood clotting, inflammation, and neoplasia. ${ }^{7}$ Many proteins and cytokines have to be bound to fibrinogen in order to fulfil their biological function. ${ }^{8}$ In cancer, increased fibrinogen activity was related to cancer cell growth and progression. ${ }^{9}$ Hyperfibrinogenemia is associated with colorectal, ${ }^{10}$ gastric, ${ }^{11}$ pancreatic $^{12}$ and lung cancer. ${ }^{13}$ In NSCLC, hyperfibrinogenemia is a predictor of survival after surgical resection and of further treatment. ${ }^{13}$ Recently, some studies have shown that hyperfibrinogenemia is more prevalent in EC and it could be a predictor for survival of EC. ${ }^{9,14,15}$ However, the significance of serum fibrinogen in operable ESCC as a predictor of survival remains unclear. The sample size in previous studies were relevant small. We had more than 1000 patients. The previous studies collected the data from many years ago. During that time, many of the patients were without lymphectomy. We only used the data from 2015 to 2018. All patients received at least a two-fields lymph node dissection. We could evalue its relation with $\mathrm{N}$ stage accurately. This large dataset enabled us to expand the analysis on subgroup of ESCC. Therefore, a real world retrospective study from a prospective database was adopted to elucidate the potential correlation between serum fibrinogen and prognostic survival.

\section{Materials And Methods}

\section{Patients And Treatment}

The project was approved by the Review Board and Ethics Committee of Henan Cancer Hospital (HCH), the affiliated Cancer Hospital of Zhengzhou University. The ethical approval number is 2018123. All patients provided written informed consent once they were in an inpatient department. This study was conducted in accordance with the Declaration of Helsinki. We included consecutive ESCC patients who underwent surgical resection at The Affiliated Cancer Hospital of Zhengzhou University/ Henan Cancer Hospital from January 1, 2015 to June 13, 2018. All patients were newly diagnosed with ESCC and had not received any treatment. The patients were excluded based on the following characteristics: a pathological diagnosed of ESCC with any components of AC; patients with evidence of cervical or celiac lymph node metastases; patients with a history or coexisting cancer other than ESCC; incomplete data of follow up results, TNM stage and the concentration of serum fibrinogen; a concomitant disease which may have influence on the concentration of serum fibrinogen, such as blood coagulation disorders, severe hypertension and liver disease; a history of acetylsalicylic acid or aspirin use within 1 month before the collection of blood samples. A total of 1331 eligible patients were included in our study. The histological diagnosis was based on the classification criteria for oesophageal tumours of the World Health Organization (WHO). Pathologic stage was determined by the 7 th edition AJCC staging system. ${ }^{16}$ Esophagectomy with extended or standard dissection of the abdominal and thoracic lymph nodes was executed.

The standardized follow-up was adopted for all patients. In the first 2 years after operation, a 3-month interval was employed and then a 6-month interval in the following $3-5$ years and yearly thereafter. The evaluation comprised a physical examination, chest CT scans, and abdominal and cervical echography.

\section{Fibrinogen Measurement}

Every patient provided 3-4 mL blood samples within 3 weeks prior to treatment. The concentrations of plasma fibrinogen were measured by the Clauss method (SIEMENS, Germany) using a coagulation analyser (Hismemakon, Japan). Following the instructions, the normal concentration of serum fibrinogen is $1.0-<4.0 \mathrm{~g} / \mathrm{L}$, and the hyperfibrinogenemia is $\geq 4.0 \mathrm{~g} / \mathrm{L}$.

\section{Statistical Analysis}

The continuous and categorical variable of fibrinogen concentration was analysed after grouping by hyperfibrinogenemia and normal levels. The association between the serum fibrinogen concentration and clinicopathological variables were tested by the chi-square test and Mann-Whitney $U$-test, respectively. Kaplan-Meier curves and Cox proportional hazards regression were used to analyse the overall survival. Covariates with a P-value $\leq 0.2$ in univariate analysis were applied in the multivariate model. All statistical calculations were performed by R language 3.4.1 for Windows. A value of $\mathrm{p}<0.05$ was considered statistically significant.

\section{Results}

A total of 1331 ESCC patients were enrolled in this study. Table 1 shows the characteristics of these patients. The patients comprised 923 males $(69.35 \%)$ and 408 females $(30.65 \%)$. The median age of the study population was 64 years (range: 41-85 years). There were 572 patients (43.63\%) with a history of drinking alcohol and 644 (48.64\%) with a history of smoking. Based on the 7 th AJCC staging system, 169 of the cases $(12.70 \%)$ were stage IA, $219(16.45 \%)$ stage IB, 226 (16.98\%) stage 
Table I Association Of Serum Fibrinogen Level With Clinicopathological Factors In Patients With Esophageal Squamous Cell Carcinoma

\begin{tabular}{|c|c|c|c|c|c|c|}
\hline \multirow[t]{2}{*}{ Factors } & \multirow{2}{*}{$\begin{array}{l}\text { Patients, } \mathbf{n} \\
\text { (\%) }\end{array}$} & \multicolumn{2}{|l|}{ Fibrinogen } & \multirow[t]{2}{*}{$p$} & \multirow{2}{*}{$\begin{array}{l}\text { Fibrinogen } \\
\text { Media (mean, 25th- } \\
\text { 75th) }\end{array}$} & \multirow[t]{2}{*}{$P$} \\
\hline & & $\begin{array}{l}\text { Normal }(2-4 g / \\
\text { L) }\end{array}$ & $\begin{array}{l}\text { Hyperfibrinogenemia } \\
\text { ( } \geq \mathbf{4 g} / \mathrm{L})\end{array}$ & & & \\
\hline $\begin{array}{l}\text { Age (years) } \\
\leq 63 \\
>63\end{array}$ & $\begin{array}{l}665(49.96) \\
666(50.04)\end{array}$ & $\begin{array}{l}605(49.67) \\
613(50.33)\end{array}$ & $\begin{array}{l}60(53.10) \\
53(46.90)\end{array}$ & 0.486 & $\begin{array}{l}2.79(2.97,2.40-3.38) \\
2.95(2.91,2.48-3.38)\end{array}$ & $0.040 *$ \\
\hline $\begin{array}{l}\text { Sex } \\
\text { Female } \\
\text { Male }\end{array}$ & $\begin{array}{l}408(30.65) \\
923(69.35)\end{array}$ & $\begin{array}{l}376(30.87) \\
842(69.13)\end{array}$ & $\begin{array}{l}32(28.32) \\
8 I(7 I .68)\end{array}$ & 0.574 & $\begin{array}{l}2.90(2.96,2.48-3.38) \\
2.86(2.94,2.40-3.38)\end{array}$ & 0.405 \\
\hline $\begin{array}{l}\text { Smoking ( } 7 \text { missing data) } \\
\text { Never } \\
\text { Ever/current }\end{array}$ & $\begin{array}{l}680(51.36) \\
644(48.64)\end{array}$ & $\begin{array}{l}628(51.86) \\
583(48.14)\end{array}$ & $\begin{array}{l}0.235 \\
52(46.02) \\
6 I(53.98)\end{array}$ & & $\begin{array}{l}0.762 \\
2.90(2.94,2.45-3.38) \\
2.86(2.95,2.43-3.38)\end{array}$ & \\
\hline $\begin{array}{l}\text { Alochol (20 missing data) } \\
\text { Never } \\
\text { Ever/current }\end{array}$ & $\begin{array}{l}739(56.37) \\
572(43.63)\end{array}$ & $\begin{array}{l}684(56.95) \\
517(43.05)\end{array}$ & $\begin{array}{l}0.159 \\
55(50.00) \\
55(50.00)\end{array}$ & & $\begin{array}{l}0.467 \\
2.86(2.92,2.45-3.33) \\
2.86(2.97,2.43-3.44)\end{array}$ & \\
\hline $\begin{array}{l}\text { PT stage } \\
\text { Tla } \\
\text { TIb } \\
\text { T2 } \\
\text { T3 } \\
\text { T4 }\end{array}$ & $\begin{array}{l}103(7.74) \\
103(7.74) \\
326(24.49) \\
665(49.96) \\
134(10.07)\end{array}$ & $\begin{array}{l}102(8.37) \\
102(8.37) \\
304(24.96) \\
593(48.69) \\
117(9.61)\end{array}$ & $\begin{array}{l}\mathrm{I}(0.88) \\
\mathrm{I}(0.88) \\
22(19.47) \\
72(63.72) \\
I 7(15.04)\end{array}$ & $<0.00 I^{*}$ & $\begin{array}{l}2.7 I(2.73,2.28-3.13) \\
2.61(2.71,2.28-3.15) \\
2.79(2.88,2.43-3.27) \\
2.95(3.02,2.48-3.56) \\
2.99(3.07,2.6 I-3.62)\end{array}$ & $<0.001 *$ \\
\hline $\begin{array}{l}\text { pN stage } \\
\text { N0 } \\
\text { NI } \\
\text { N2 } \\
\text { N3 }\end{array}$ & $\begin{array}{l}838(62.96) \\
301(22.61) \\
156(11.72) \\
36(2.70)\end{array}$ & $\begin{array}{l}779(63.96) \\
265(21.76) \\
140(11.49) \\
34(2.79)\end{array}$ & $\begin{array}{l}59(52.21) \\
36(31.86) \\
16(14.16) \\
2(1.77)\end{array}$ & 0.109 & $\begin{array}{l}2.83(2.90,2.40-3.33) \\
2.95(3.01,2.48-3.44) \\
2.88(2.97,2.39-3.56) \\
3.10(3.15,2.8 I-3.31)\end{array}$ & $0.030 *$ \\
\hline $\begin{array}{l}\text { PTNM staging } \\
\text { IA } \\
\text { IB } \\
\text { IIA } \\
\text { IIB } \\
\text { IIIA } \\
\text { IIIB } \\
\text { IIIC }\end{array}$ & $\begin{array}{l}169(12.70) \\
219(16.45) \\
226(16.98) \\
238(17.88) \\
219(16.45) \\
95(7.14) \\
165(12.40)\end{array}$ & $\begin{array}{l}167(13.71) \\
205(16.83) \\
204(16.75) \\
218(17.90) \\
192(15.76) \\
86(7.06) \\
146(11.99)\end{array}$ & $\begin{array}{l}<\left.0.00\right|^{*} \\
2(1.72) \\
14(12.07) \\
22(18.97) \\
21(18.10) \\
28(24.14) \\
9(7.76) \\
20(17.24)\end{array}$ & & $\begin{array}{l}<0.001 * \\
2.71(2.72,2.29-3.13) \\
2.86(2.93,2.46-3.36) \\
2.90(2.98,2.44-3.50) \\
2.83(2.92,2.43-3.33) \\
2.90(2.98,2.44-3.44) \\
2.99(3.03,2.53-3.56) \\
2.99(3.08,2.68-3.62)\end{array}$ & \\
\hline
\end{tabular}

Note: *Statistically significant $(p<0.05)$.

Abbreviations: pT, pathological tumor; pN, pathological node; pTNM, pathological tumor/node/metastasis.

IIA, 238 (17.88\%) stage IIB, 219 (16.45\%) stage IIIA, 95 (7.14\%) stage IIIB and $165(12.40 \%)$ stage IIIC.

\section{Characteristics Of Patients}

The median concentration of serum fibrinogen was $2.86 \mathrm{~g} / \mathrm{L}$ in all patients (range: $1.01-4.91 \mathrm{~g} / \mathrm{L}$ ). A total of 113 patients (8.49\%) had hyperfibrinogenemia (4 g/L) and $1218(91.51 \%)$ had a normal serum fibrinogen concentration $(<4 \mathrm{~g} / \mathrm{L})$. Serum fibrinogen concentration was significantly associated with pathological stage. The continuous variable of fibrinogen concentration was significantly higher in early stages (II and I) than in advanced stages (III) (2.90 vs 3.02, $\mathrm{p}=0.003)$. The analysis of categorical variables found that it was also related to age (Table 1).

\section{Survival}

The follow-up was conducted from 0.22 to 36.4 months, with a mean period of 15.7 months. The 3 -year overall survival 


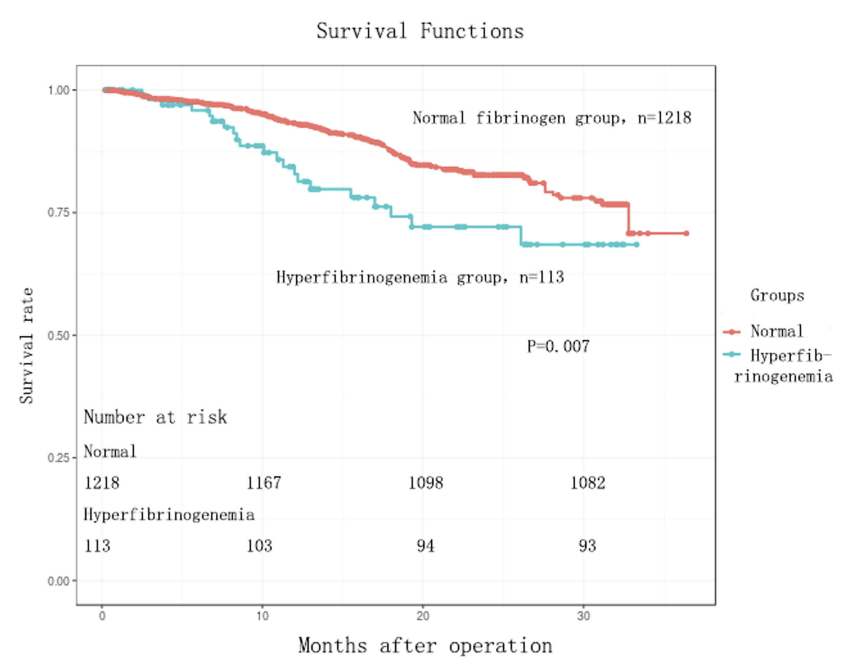

Figure I Kaplan-Meier overall survival analysis of ESCC patients $(n=1331)$. Overall survival (OS) subdivided by serum fibrinogen level (log rank test, $P=0.007$ ).

rate was $70.63 \%$. The concentration of serum fibrinogen was inversely correlated with overall survival. Patients with a normal serum fibrinogen concentration had higher 33-month overall survival rates (70.77 vs $68.49 \%$ ) than those with hyperfibrinogenemia. The patients with hyperfibrinogenemia had a worse overall survival (Figure 1) than patients with normal fibrinogen. This was indicated by Kaplan-Meier survival curves and shown in Figure 1. Multivariate Cox proportional hazards model analysis revealed that hyperfibrinogenemia was an independent prognostic factors in operable ESCC $(\mathrm{P}=0.007$, Table 2$)$. With adjustment for covariates, we found that hyperfibrinogenemia patients had $67.2 \%$ higher risks of death Hazard Ratio $(\mathrm{HR})=1.672$, 95\% CI: 1.043-2.681. Hyperfibrinogenemia had an elevated risk of death compared to normal fibrinogen levels.

\section{Subgroup Analysis}

Univariate survival analyses stratified by age, gender, smoking status, alcohol consumption, and pathological stage were conducted. We found that hyperfibrinogenemia was associated with decreased OS in patients with a young age $\leq 63$, female gender, never-smoking, never alcohol consumption, N0 stage (Figure 2A) and early pathological stage (I-II) (Figure 2B) $(\mathrm{P}<0.05$, Table 3$)$. However, there was no significant association between serum fibrinogen and OS in patients with an age $>63$, male, smoking, alcohol consumption, N1-3, and advanced pathological stage III-IV $(\mathrm{P}>0.05)$.

\section{Discussion}

The association between the progression of malignancies and coagulation has been explored for many years. An increasing number of studies have demonstrated that serum fibrinogen was associated with tumour invasion, progression and unfavourable prognosis in colorectal, ${ }^{12}$ lung, ${ }^{13}$ gastric ${ }^{11}$ and EC. ${ }^{14}$ A recent study with a large cohort indicated that hyperfibrinogenemia was significantly associated with poor prognosis of operable EC. ${ }^{14,15}$ However, they explored the patients from 2000 $2008 .{ }^{14}$ During that time, lymph node samples were also accepted. Many patients without any lymphadenectomy were included, which is not currently acceptable and may be a confounding factor and significantly affect the overall survival. In the current study, we adopted the linkdoc data technology, used a prospective database and performed a large cohort retrospective study containing 1331 ESCC with detailed follow-up data from 2015 to 2018. All patients received at least a two-fields lymph node dissection. The confounding factors, potential bias and

Table 2 Univariate And Multivariate Analyses Of Overall Survival In I33I Cases Of Esophageal Squamous Carcinoma Patients

\begin{tabular}{|c|c|c|c|c|c|c|}
\hline \multirow[t]{2}{*}{ Variables } & \multicolumn{3}{|c|}{ Univariate Analysis } & \multicolumn{3}{|c|}{ Multivariate Analysis } \\
\hline & HR & $95 \% \mathrm{Cl}$ & $P$ value & HR & $95 \% \mathrm{Cl}$ & $P$ value \\
\hline Age ( $\leq 63$ years vs $>63$ years) & 0.959 & $0.703-1.307$ & 0.790 & & & \\
\hline Gender (male vs female) & 1.207 & $0.853-1.708$ & 0.289 & & & \\
\hline Smoking (Yes vs No) & 1.284 & $0.940-1.754$ & 0.116 & 0.860 & $0.557-1.326$ & 0.859 \\
\hline Alochol (Yes vs No) & 1.444 & $0.057-1.973$ & 0.021 & 1.470 & $0.956-2.260$ & 0.080 \\
\hline T staging (TI-2 vs T3-4) & 2.212 & $1.536-3.184$ & $<0.00 I^{*}$ & 1.694 & $1.087-2.638$ & $0.020 *$ \\
\hline $\mathrm{N}$ staging (N0 vs NI-3) & 3.527 & $2.55 \mathrm{I}-4.877$ & $<0.00 I^{*}$ & 2.973 & $1.732-5.103$ & $<0.00 I^{*}$ \\
\hline pTNM staging 7th ( I , II vs III) & 0.314 & $0.228-0.433$ & $<0.00 I^{*}$ & 0.910 & $0.503-1.644$ & 0.754 \\
\hline Fibrinogen (normal vs high) & 1.873 & $1.183-2.964$ & $0.007^{*}$ & 1.672 & $|.043-2.68|$ & $0.033^{*}$ \\
\hline
\end{tabular}

Note: *Statistically significant $(p<0.05)$.

Abbreviations: HR, hazard ratio; $\mathrm{Cl}$, confidence interval; PTNM, pathological tumor/node/metastasis. 


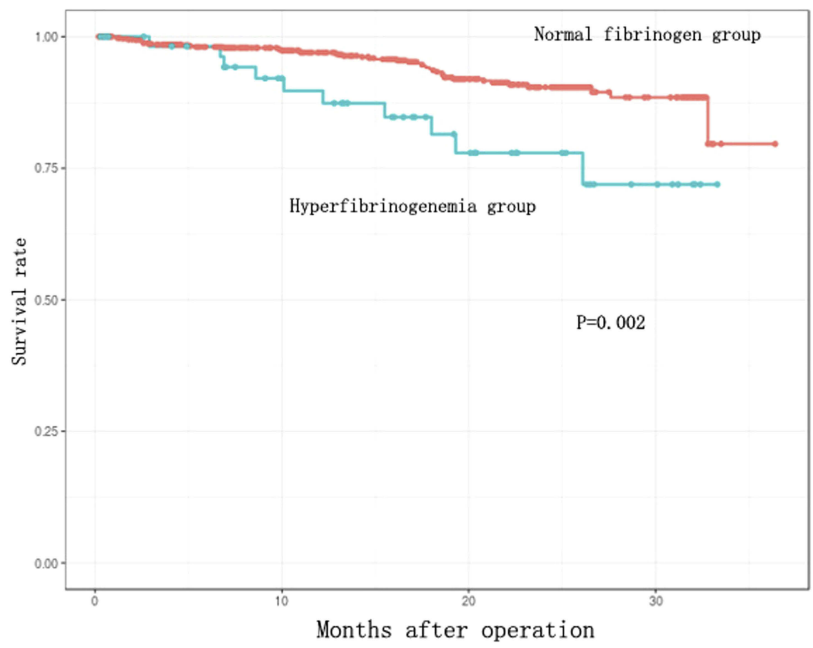

B

Survival Functions

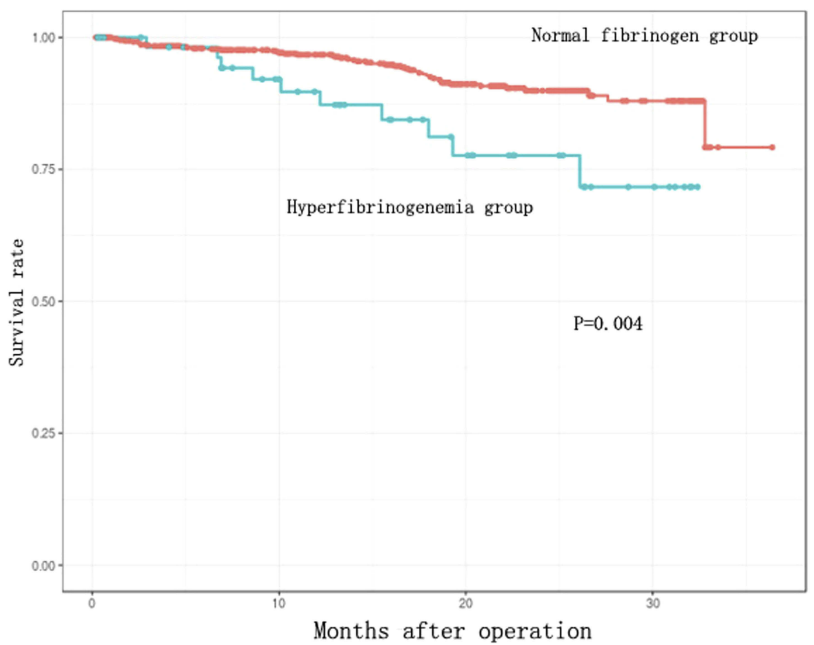

Figure 2 Kaplan-Meier Subgroup overall survival analysis of ESCC. (A) Kaplan-Meier curves of overall survival (OS) subdivided by serum fibrinogen level in patients with pathological NO ESCC $(n=838)$ (log rank test, $P=0.002)$, (B) Kaplan-Meier curves of overall survival $(O S)$ subdivided by serum fibrinogen level in patients with pathological stage I-II ESCC $(n=852)(\log r a n k$ test, $P=0.004)$.

heterogeneity might be minimized. This large dataset enabled us to expand the analysis on subgroup of ESCC. For example, the hyperfibrinogenemia is a more useful prognosis factor in early TNM stage I-II and N0 ESCC. This is the largest sample size study evaluating the prognosis of serum fibrinogen in predicting the OS of operable ESCC until now.

Our report suggested that hyperfibrinogenemia was significantly related to advanced pathological $\mathrm{T}$ stage, TNM stage and poor prognosis. The hyperfibrinogenemia was indicated as an independent prognostic factor in ESCC by multivariate analysis. We also found that the concentration of fibrinogen level was closely associated with age, advanced pathological T stage, lymph node metastasis and TNM stage. Our results were consistent with previous studies. ${ }^{14,17,18}$ We all demonstrated that hyperfibrinogenemia was significantly related to the depth of invasion and advanced pathological stages in ESCC. ${ }^{14,17,18}$ However, Zhang et al $^{14}$ reported that the increased serum fibrinogen was also associated with smoking and alcohol consumption. Our data showed a different conclusion. These data suggest that the concentration of serum fibrinogen before treatment might be helpful for classification of clinical $\mathrm{T}$ staging. Interestingly, our study demonstrated that hyperfibrinogenemia was not correlated with the $\mathrm{N}$ stage, consistent with previous studies ${ }^{13,19}$ and inconsistent with the report of Zhang et $\mathrm{al}^{14}$. Although the study of Zhang et $\mathrm{al}^{14}$ had a large sample size, many of the patients were without lymphectomy, and therefore, it may not be credible. Hyperfibrinogenemia might serve as a local regulator rather than a systematic mediator for ESCC. The major strength of our study is the large cohort from 3 recent years. Hyperfibrinogenemia alone cannot be a useful predictor for lymph node status but can be for the T status.

In this study, the concentration of serum fibrinogen was correlated with patient outcome. The hyperfibrinogenemia patients had a decreased OS compared to those with normal levels. Moreover, a multivariate analysis showed that the pretreatment serum fibrinogen was an independent prognostic biomarker in operable ESCC patients. The hyperfibrinogenemia patients had 1.672 times the risk of death of those with normal fibrinogen level. These results are consistent with previous studies based on relatively small cohorts ${ }^{18}$ and the old data from 10 years ago. ${ }^{14}$ In the report by Zhang et $\mathrm{al}^{18}$ and a report by another Zhang et al, ${ }^{14}$ patients with hyperfibrinogenemia exhibited a 1.27-fold and 1.20-fold increased relative risk of death compared patients with normal fibrinogen level, respectively.

More importantly, within the large population of ESCC, we conducted a subgroup analysis and revealed that hyperfibrinogenemia was associated with decreased OS in ESCC patients with younger age ( $\leq 63$ years), female, without a history of smoking and alcohol consumption, pathological N0 and early pathological stage (I-II). However, for patients with advanced pathological $\mathrm{N}$ stage and TNM stage (III-IV), serum fibrinogen was not associated with OS. Alcohol consumption and smoking may activate more oncogenes and dismissed the 
Table 3 Subgroup Analysis By Serum Fibrinogen For Overall Survival In Patients With Esophageal Squamous Cell Carcinoma

\begin{tabular}{|c|c|c|}
\hline \multirow[t]{2}{*}{ Prognostic Factors } & \multicolumn{2}{|c|}{ Overall Survival } \\
\hline & $\operatorname{Mean}(\mathrm{m})$ & $p$ \\
\hline Age(years) & & \\
\hline$\leq 63$ & & $0.011 *$ \\
\hline Normal level & 30.76 & \\
\hline Hyperfibrinogenemia & 27.21 & \\
\hline$>63$ & & 0.201 \\
\hline Normal level & 29.33 & \\
\hline Hyperfibrinogenemia & 27.44 & \\
\hline Sex & & \\
\hline Female & & $0.002 *$ \\
\hline Normal level & 31.06 & \\
\hline Hyperfibrinogenemia & 25.74 & \\
\hline Male & & 0.180 \\
\hline Normal level & 29.43 & \\
\hline Hyperfibrinogenemia & 27.90 & \\
\hline Smoking (7 missing data) & & \\
\hline Never & & $<0.001 *$ \\
\hline Normal level & 31.05 & \\
\hline Hyperfibrinogenemia & 25.42 & \\
\hline Ever/current & & 0.180 \\
\hline Normal level & 29.43 & \\
\hline Hyperfibrinogenemia & 27.90 & \\
\hline Alochol (20 missing data) & & \\
\hline Never & & $<0.001 *$ \\
\hline Normal level & 31.15 & \\
\hline Hyperfibrinogenemia & 26.39 & \\
\hline Ever/current & & 0.844 \\
\hline Normal level & 28.72 & \\
\hline Hyperfibrinogenemia & 28.31 & \\
\hline pT stage & & \\
\hline TI-2 & & 0.123 \\
\hline Hyperfibrinogenemia & 31.79 & \\
\hline Ever/current & 28.98 & \\
\hline T3-4 & & 0.065 \\
\hline Hyperfibrinogenemia & 28.77 & \\
\hline Ever/current & 26.49 & \\
\hline $\mathrm{pN}$ stage & & \\
\hline No & & $0.002 *$ \\
\hline Hyperfibrinogenemia & 32.53 & \\
\hline Ever/current & 29.34 & \\
\hline NI-3 & & 0.323 \\
\hline Hyperfibrinogenemia & 26.50 & \\
\hline Ever/current & 24.62 & \\
\hline
\end{tabular}

(Continued)
Table 3 (Continued).

\begin{tabular}{|l|l|l|}
\hline Prognostic Factors & \multicolumn{2}{|l|}{ Overall Survival } \\
\cline { 2 - 3 } & Mean(m) & $\mathbf{p}$ \\
\hline PTNM staging & & \\
Stage I-II & & $0.004^{*}$ \\
Hyperfibrinogenemia & 32.01 & \\
Ever/current & 28.96 & \\
\hline Stage III & & 0.303 \\
Hyperfibrinogenemia & 26.93 & \\
Ever/current & 25.10 & \\
\hline
\end{tabular}

Note: *Statistically significant $(p<0.05)$.

Abbreviations: $\mathrm{m}$, month; $\mathrm{Cl}$, confidence interval; pTNM, pathological tumor/ node/metastasis.

efforts of serum fibrinogen. ${ }^{20}$ They may contribute to the ESCC progression through different signal pathways. ${ }^{21}$ These might be hints for laboratory studies to determine the biological function of serum fibrinogen. It also might serve as a useful predictor for survival in patients with ESCC, especially in those with pathological early stage and N0. Further exploration is needed to determine whether the pretreatment serum fibrinogen level is useful in identifying those who will benefit from perioperative treatment.

This study was limited in its single-centre design and retrospective nature. The selection bias cannot be avoided. Another main problem was the lack of recurrence data. The information on recurrence is still being contributed by the linkdoc database, so we cannot perform an analysis of DFS.

In summary, hyperfibrinogenemia is an independent prognostic biomarker for overall survival in operable ESCC, especially in pathological stage I-II ESCC and N0 patients. In the future, laboratory research as well as prospective clinical trials should be employed to confirm the biological function and its prognostic significance in ESCC.

\section{Acknowledgments}

$\mathrm{YZ}$ is sponsored by the Henan Province Ministry of Education (Grant Number 17A320048), China.

\section{Funding}

This project was supported by the Henan Provincial Public Health Authority (Grant Number 201501003), Henan Province Ministry of Education (Grant Number. 
17A320048), and Wu Jieping, China (Grant Numbers 320.6799 .15062 and 320.2730.1892).

\section{Disclosure}

The authors report no conflicts of interest in this work.

\section{References}

1. Jemal A, Bray F, Center MM, Ferlay J, Ward E, Forman D. Global cancer statistics. CA Cancer J Clin. 2011;61(2):69-90. doi:10.3322/ caac. 20107

2. Chen W, Zheng R, Baade PD, et al. Cancer statistics in China, 2015. CA Cancer J Clin. 2016;66(2):115-132. doi:10.3322/caac.21338

3. Torre LA, Bray F, Siegel RL, Ferlay J, Lortet-Tieulent J, Jemal A. Global cancer statistics, 2012. CA Cancer J Clin. 2015;65(2):87-108. doi:10.3322/caac. 21262

4. van Hagen P, Hulshof MC, van Lanschot JJ, et al. Preoperative chemoradiotherapy for esophageal or junctional cancer. $N$ Engl J Med. 2012;366(22):2074-2084. doi:10.1056/NEJMoa1112088

5. Meng H, Wang K, Chen X, et al. MicroRNA-330-3p functions as an oncogene in human esophageal cancer by targeting programmed cell death 4. Am J Cancer Res. 2015;5(3):1062-1075.

6. Chen M, Huang J, Zhu Z, Zhang J, Li K. Systematic review and metaanalysis of tumor biomarkers in predicting prognosis in esophageal cancer. BMC Cancer. 2013;13:539. doi:10.1186/1471-2407-13-539

7. Simpson-Haidaris PJ, Rybarczyk B. Tumors and fibrinogen. The role of fibrinogen as an extracellular matrix protein. Ann N Y Acad Sci. 2001;936:406-425.

8. Lu J, Huang C-M, Zheng C-H, et al. Consideration of tumor size improves the accuracy of TNM predictions in patients with gastric cancer after curative gastrectomy. Surg Oncol. 2013;22(3):167-171. doi:10.1016/j.suronc.2013.05.002

9. Lv GY, Yu Y, An L, Sun XD, Sun DW. Preoperative plasma fibrinogen is associated with poor prognosis in esophageal carcinoma: a meta-analysis. Clin Transl Oncol. 2017;20(7):853-861.

10. Adams GN, Rosenfeldt L, Frederick M, et al. Colon cancer growth and dissemination relies upon thrombin, stromal PAR-1, and fibrinogen. Cancer Res. 2015;75(19):4235-4243. doi:10.1158/0008-5472.CAN-150964

11. Yu X, Hu F, Yao Q, Li C, Zhang H, Xue Y. Serum fibrinogen levels are positively correlated with advanced tumor stage and poor survival in patients with gastric cancer undergoing gastrectomy: a large cohort retrospective study. BMC Cancer. 2016;16:480. doi:10.1186/s12885-016$2510-\mathrm{z}$
12. Cao J, Fu Z, Gao L, et al. Evaluation of serum D-dimer, fibrinogen, and CA19-9 for postoperative monitoring and survival prediction in resectable pancreatic carcinoma. World J Surg Oncol. 2017;15(1):48. doi:10.1186/s12957-017-1104-9

13. Sheng L, Luo M, Sun X, Lin N, Mao W, Su D. Serum fibrinogen is an independent prognostic factor in operable nonsmall cell lung cancer. Int J Cancer. 2013;133(11):2720-2725.

14. Zhang SS, Lei YY, Cai XL, et al. Preoperative serum fibrinogen is an independent prognostic factor in operable esophageal cancer. Oncotarget. 2016;7(18):25461-25469. doi:10.18632/oncotarget.8171

15. Wakatsuki K, Matsumoto S, Migita K, et al. Preoperative plasma fibrinogen is associated with lymph node metastasis and predicts prognosis in resectable esophageal cancer. World J Surg. 2017;41 (8):2068-2077. doi:10.1007/s00268-017-3991-x

16. Rice TW, Blackstone EH, Rusch VW. 7th edition of the AJCC Cancer Staging Manual: esophagus and esophagogastric junction. Ann Surg Oncol. 2010;17(7):1721-1724. doi:10.1245/s10434-0101024-1

17. Wang J, Liu H, Shao N, et al. The clinical significance of preoperative plasma fibrinogen level and platelet count in resectable esophageal squamous cell carcinoma. World J Surg Oncol. 2015;13:157.

18. Zhang D, Zhou X, Bao W, et al. Plasma fibrinogen levels are correlated with postoperative distant metastasis and prognosis in esophageal squamous cell carcinoma. Oncotarget. 2015;6 (35):38410-38420. doi:10.18632/oncotarget.4800

19. Jones JM, McGonigle NC, McAnespie M, Cran GW, Graham AN. Plasma fibrinogen and serum C-reactive protein are associated with non-small cell lung cancer. Lung Cancer. 2006;53(1):97-101. doi:10.1016/j.lungcan.2006.03.012

20. Haugvik SP, Basim Ibrahim I, Hedenstrom P, et al. Smoking, alcohol and family history of cancer as risk factors for small intestinal neuroendocrine tumors: a systematic review and meta-analysis Scand J Gastroenterol. 2017;52(8):797-802. doi:10.1080/00365521. 2017.1310290

21. Zhang F, Wang Y, Sun P, et al. Fibrinogen promotes malignant biological tumor behavior involving epithelial-mesenchymal transition via the p-AKT/p-mTOR pathway in esophageal squamous cell carcinoma. J Cancer Res Clin Oncol. 2017;143(12):2413-2424. doi:10.1007/s00432-017-2493-4

\section{Publish your work in this journal}

Cancer Management and Research is an international, peer-reviewed open access journal focusing on cancer research and the optimal use of preventative and integrated treatment interventions to achieve improved outcomes, enhanced survival and quality of life for the cancer patient.
The manuscript management system is completely online and includes a very quick and fair peer-review system, which is all easy to use. Visit http://www.dovepress.com/testimonials.php to read real quotes from published authors. 